\title{
Merrf Syndrome and Refractory Status Epilepticus
}

\author{
Ilirjana Bakalli ${ }^{1}$, Vahe Mokini ${ }^{2}$ \\ ${ }^{1}$ PICU - University Hospital Center —MotheiTheresa", Tirana - Albania \\ ${ }^{2}$ Department of Genetics- University Hospital Center —Motheirheresa”, Tirana - Albania
}

\begin{abstract}
MERRF syndrome (or Myoclonic Epilepsy with Ragged Red Fibers) is a mitochondrial disease maternally-inherited. In this progressive disorder, status epilepticus is common and highly resistant to treatment including generalized anesthesia. We report two cases with Merrf syndrome (sister and brother), presented with status epilepticus refractory even to Thiopental, Propofol and Midazolam. In the same family is and another girl, diagnosed with Merrf syndrome. Given that it wasn't possible to stop the refractory status in these cases, we suggest Ketamine as an alternative to general anesthesia as for blocking seizure activity, as for the potential neuroprotective effect.
\end{abstract}

Keywords: Merrf syndrome, status epilepticus, ketamine.

\section{Introduction}

MERRF syndrome (or Myoclonic Epilepsy with Ragged Red Fibers) is a mitochondrial disease, caused by a maternally-inherited mutation at position 8344 in the mitochondrial genome. This point mutation disrupts the mitochondrial gene for tRNA-Lys and so disrupts synthesis of proteins essential for oxidative phosphorylation.(1) The characteristic symptom of MERRF syndrome are myoclonic seizures that are usually sudden, brief, jerking, spasms that can affect the limbs or the entire body.(2) Status epilepticus can be severe and refractory even to Midazolam, Thiopental and propofol. In such cases we have failure of GABA-ergic anesthetics, so failure of inhibition mechanisms. On the other hand glutamate activation of NMDA receptors give excitatory effects and lead to neurologic injury with cell death. With the development of $\mathrm{GABA}_{\mathrm{A}}$ resistance, SE increase the sensitivity to NMDA antagonists.(3) Ketamine inhibits NMDA (N-methyl-D-aspartate) receptors by binding to the phencyclidine site on the NMDA-receptor protein, that's why it can be an alternative to general anesthesia as for blocking seizure activity, as for the potential neuroprotective effect.

\section{Case Reports}

We report three cases of Merrf syndrome, all from a family. First child, ten years old, had the first presentation in hospital with a refractory myoclonic status epilepticus. According to the family, it was the first time that the child posed such a state. The status was refractory to Diazepam (two times with $0.3 \mathrm{mg} / \mathrm{kg} \mathrm{IV}$ ), Phenytoine (20 mg/kg IV) and Phenobarbital ( loading dose 20mg/kg IV). No changes were observed at the CT of the head, performed within a few hours of presentation. Naturally the girl has been intubated and maintained in mechanical ventilation. Despite continuous treatment with Thiopental $(5 \mathrm{mg} / \mathrm{kg}$ loading dose, $5 \mathrm{mg} / \mathrm{kg} / \mathrm{h}$ maintenance dose), Midazolam (0.3 mg/kg loading dose, $0.3 \mu \mathrm{g} / \mathrm{kg} / \mathrm{h}$ maintenance dose) and Propofol (2 $\mathrm{mg} / \mathrm{kg}$ loading dose, $5 \mathrm{mg} / \mathrm{kg} / \mathrm{h}$ maintenance dose), the status didn't stop for any moment). The girl died three days after admission. At that moment we haven't done a checkup for the other siblings, to could diagnose and maybe deciding about the treatment with Levetiracetam or another antiepileptic which is of choice in such cases.

Two years after the girl, her 13 years old brother has been admitted at our PICU with myoclonic status epilepticus, refractory even him to midazolam, phenytoine, thiopental and propofol. Asking carefully the children's relatives, we learn that an uncle of the children has died young, and the genetic tree of the child's mother had other cases of new age deaths, without a clear cause. By the help of our geneticist doctor we made the diagnosis of Merrf syndrome, but we couldn `t help even him for the refractory status in which he presented. (He died after some days)

In the same family is and another girl, which has been too diagnosed for Merrf syndrome (mutation A8344G analyzing the DNA of lymphocytes), and presents epilepsy.

\section{Discussion}

The most common MERRF mutation is A8344G (1), which account for over $80 \%$ of the cases, mutation that we found even in our cases. This is a maternally inherited disease. A female with the mutation transmits the mutation to all of her offspring.

In this progressive disorder, SE is common and highly resistant to treatment including generalized anesthesia(1), refractory even to Thiopental and propofol such in our case reports. In a recent series, 11 out of 26 patients with mitochondrial disease died, and in over $80 \%$ malignant SE was the recorded cause of death. (4)

Refractory status epilepticus (RSE) is an important and serious clinical problem that typically requires prolonged and high-level intensive care, and is often associated with poor outcome such in our cases. $(2,5,6,7)$ The overall mortality of SE is about $20 \%$ but varies widely, primarily on the basis of age, etiology, and duration of SE.(3) In a systemic review of Claassen at al. (8) for refractory status from 193 patients, forty-eight percent of patients died. Even with current best practice, mortality in patients who experience refractory generalized convulsive SE is about 


\section{International Journal of Science and Research (IJSR) \\ ISSN (Online): 2319-7064 \\ Index Copernicus Value (2013): 6.14 | Impact Factor (2015): 6.391}

$50 \%$ and only the minority return to their premorbid functional baseline.(9)

Several intravenous agents have been used for RSE; however, problems occur with their toxicity and/or effectiveness. $(7,10,11,12)$ The most common treatment protocols for status epilepticus specify intravenous benzodiazepine (either lorazepam or diazepam) as initial antiepileptic drug (AED) therapy, followed by phenytoin or fosphenytoin and then phenobarbital if seizures continue (according these protocol we treat and our children). (2,7) Most patients respond to the first or second AED. However, when the patient fails to respond to this standard, initial treatment, the patient is considered to be refractory" and requires additional, more aggressive treatment.

Neuronal injury is probably mediated by excess excitation via activation of the N-methyl-D-aspartate (NMDA) subtype of glutamate receptors and consequent elevated intracellular calcium that causes acute necrosis and delayed apoptotic cell death.(13)

During RSE glutamate activation of NMDA receptors give excitatory effects and lead also to neurologic injury with cell death. With the development of $\mathrm{GABA}_{\mathrm{A}}$ resistance (failure of inhibition mechanisms in cases refractory to GABA-ergic anesthetics), SE increase the sensitivity to NMDA antagonists. Therefore, new treatment options are urgently needed. The ideal new drug for refractory RSE would be one that has the ability to stop seizures more effectively and safely than current drugs, and that has neuroprotective properties to prevent the brain damage and neurological morbidity caused by RSE(9).

A few cases suggest strong anticonvulsant properties of ketamine even after failure of GABA-ergic anesthetics.(2,10,11,12,14,15,16) Ketamine inhibits NMDA (N-methyl-D-aspartate) receptors by binding to the phencyclidine site on the NMDA-receptor protein, blocking seizure activity, and having a potential neuroprotective effect. In addition it can increase blood pressure due to its sympathomimetic properties. $(6,10)$ These characteristics make it a reasonable potential choice as adjunctive therapy in RSE.

In an abstract, Bleck and colleagues(11,17) described their experience with the use of ketamine in seven critically ill patients with RSE. Their main observation was that ketamine produced electrographic seizure control in over half the patients without causing hemodynamic instability. A case report by Sheth and Gidal(15) also provides evidence for the potential utility of ketamine in extremely refractory cases.

The general (dissociative) anesthetic dose is $1-5 \mathrm{mg} / \mathrm{kg}$, with infusion of $1-5 \mathrm{mg} / \mathrm{kg} /$ hour (20-80 $\mathrm{mcg} / \mathrm{kg} /$ minute).(10) It is recommended that it should be administered with a benzodiazepine in an attempt to decrease later psychiatric side effects.(16)

Naturally, not only to give hope to this mother, but also for other similar cases with Merrf syndrome, given the RSE, even to phenytoin, thiopental and propofol, after failure of GABAergic anesthetics, we suggest to incorporate ketamine into the therapeutic protocol for the strong anticonvulsant properties due to increased NMDA receptor expression with ongoing seizure activity.

\section{Conclusion}

Future treatment of refractory SE should involve both GABA -ergic anesthetics and NMDA antagonists to stop seizure activity and prevent acute and delayed neuronal injury.

For patients experiencing prolonged status epilepticus, refractory even to Thiopental and propofol, ketamine may be an alternative to general anesthesia.

\section{References}

[1] MERRF syndrome - Available at: http://en.wikipedia.org/wiki/Merrfsyndrome

[2] Richard E. Behrman; Robert M. Kliegman, ; Hal B. Jenson; Nelson Textbook of Pediatrics $17^{\text {th }}$ edition Saunders (Elsevier Science)USA, 2004. 2026-7

[3] Manno EM., New management strategies in the treatment of status epilepticus. Mayo Clin Proc. 2003;78:508-518

[4] Tzoulis, C., Engelsen, B.A., Telstad, W., Aasly, J., Zeviani, M., Winterthun,S.et al. The spectrum of clinical disease caused by the A467T and W748S POLG mutations: a study of 26 cases. Brain 2006. 129, 1685-1692.

[5] Status epilepticus. Available http://en.wikipedia.org/wiki/Status_epilepticus

[6] David G. Nichols. Rogers'Textbook of Pediatric Intensive Care - Wolters Kluwer/ Lippincott Williams \& Wilkins Philadephia, 2008 ; 829-925.

[7] Wasterlain CG., Chen JW.Y.,Mechanistic and pharmacologic aspects of status epilepticus and its treatment with new antiepileptic drugs.Epilepsia.2008; 49: 63-73.

[8] Claassen J, Hirsch LJ, Emerson RG, Mayer SA. Treatment of refractory status epilepticus epilepticus with pentobarbital, propofol, or midazolam: a systemic review. Epilepsia. 2002 Feb;43(2):146-53

[9] Kälviäinen R, Eriksson K, Parviainen I.Refractory generalized convulsive status epilepticus: a guide to treatment. CNS Drugs. 2005;19(9):759-68

[10] Thomas P. Bleck. An Expert Interview With Thomas P. Bleck, MD: Refractory Status Epilepticus. Available at: http://www.medscape.com/viewarticle/469550_4

[11] Ketamine in status epilepticus. Available at: http://www.vetcontact.com/en/art.php?a=1205\&t=

[12] Borris DJ, Bertram EH., Kapur J. Ketamine controls prolonged status epilepticus. Epilepsy research 2000; 42(2):117-122.

[13] Fountain NB. Status epilepticus: risk factors and complications. Epilepsia.2000;41 Suppl 2:23-30.

[14] Prüss H, Holtkamp M. Ketamine successfully terminates malignant status epilepticus. Epilepsy Res. 2008 Dec;82(23):219-22.

[15] Sheth, R.D., Gidal, B.E., 1998. Refractory status epilepticus: response to ketamine. Neurology 51, 1765-6.

[16] Nathan BN, Smith TL, Bleck TP. The use of ketamine in refractory status epilepticus. Neurology. 2002;58:A197. Durham D. Management of status epilepticus. Crit Care Resusc. 1999; 1(4):344-53

[17] DH Lowenstein. The management of refractory status epilepticus: an update. Epilepsia, 2006; 47(1), 35-40. 